\title{
Ketorolac, a new non-opioid analgesic: a single-blind trial versus buprenorphine in pain after orthopaedic surgery
}

José Cañadell-Carafi, M.D., Alvaro Moreno-Londoño, M.D., and Bosco GonzálezCaudevilla,* M.D.

Clínica Universitaria de Navarra, Clínica Universitaria, Universidad de Navarra, Pamplona, and *Syntex Latino, S.A., Barcelona, Spain

\section{SUMMARY}

A randomized single-blind, double-observer trial was performed to evaluate the efficacy of a new non-steroidal anti-inflammatory analgesic drug, ketorolac, in the treatment of post-orthopaedic surgery pain. Sixty patients with moderate to severe pain were studied; 30 patients were treated with ketorolac at a dose of $30 \mathrm{mg}$ intramuscularly up to 4-times a day, whilst the other 30 patients received $0.3 \mathrm{mg}$ buprenorphine intramuscularly up to 4-times a day. A significant reduction in the severity of the pain was recorded in both groups. Throughout the study, comparable efficacy was found between the two therapies although buprenorphine showed greater efficacy during the first 8 hours. Interestingly, the withdrawals due to adverse events were significantly lens in the ketorolac group $(\mathrm{p}<0.001)$. This study, therefore, suggests that ketorolac may be a useful and more acceptable alternative to buprenorphine in the treatment of postorthopaedic surgery pain.

\section{KEY WORDS}

Ketorolac, buprenorphine, analgesics, pain, post-operative. 


\section{INTRODUCTION}

After surgery, most patients require analgesic medication. These analgesics should be chosen carefully to balance the benefits of their efficacy with the potential for sideeffects which such drugs may cause. At present, opioids are the mainstay of analgesic treatment but are controlled drugs in most countries; these stringent controls delay their administration and increase nursing workloads.

Ketorolac is a new non-steroidal anti-inflammatory drug. ${ }^{3}$ Its chemical name is $( \pm)-5$ benzoy1-2,3-dihydro-1H-pyrrolizine-1-carboxylic acid, 2-amino-2-(hydroxy-methyl)1,3-propanediol. Ketorolac is also a powerful analgesic and as such it presents a potentially useful and more acceptable alternative to opiates for the relief of moderate and severe pain. ${ }^{7}$ Its analgesic action is mostly attributable to its ability to inhibit the cyclo-oxygenase enzymes involved in prostaglandin synthesis. ${ }^{7}$ Ketorolac is well absorbed after oral administration and has an excellent tolerance profile. ${ }^{1.4-6}$ It is without opioid side-effects (or any demonstrable opiate receptor binding) ${ }^{2}$ and thus has no addictive potential.

The present study was designed to evaluate the efficacy of intramuscular ketorolac therapy for the treatment of pain, and compare this with buprenorphine in a single-blind trial in surgical patients.

\section{PATIENTS AND METHODS}

Sixty patients, of either sex, aged 18 to 70 years, suffering moderate to severe pain after orthopaedic surgery (total hip replacement, lumbar arthrodesis) were enrolled in the study. Patients with significant impairment of brain, liver, kidney, lung or heart function were excluded, as were those displaying perturbed endocrine function or having gastric or duodenal ulcers. Patients with a history of asthma, allergy to salicylates or nonsteroidal anti-inflammatory drugs in general, patients known to be hypersensitive to buprenorphine, addicted to alcohol or other drugs, and pregnant or nursing women were also excluded.

Patients had to give verbal informed consent to participate in the study and were then randomly allocated to receive $30 \mathrm{mg}$ intramuscular ketorolac up to 4-times a day or 0.3 $\mathrm{mg}$ intramuscular buprenorphine up to 4-times a day. Rescue medication of $30 \mathrm{mg}$ pentazocine was available, if required. No pentazocine was allowed within the first 2 hours after the initial dose of the trial drug. No analgesics or drugs binding strongly to plasma proteins were allowed in the 6 hours before the commencement of the study. Treatment continued for 3 days.

Patients underwent a medical examination before entry into the study. Immediately before the first dose of study drug they were questioned as to the severity of their pain. Pain was evaluated on a $100 \mathrm{~mm}$ visual analogue scale, marked 'no pain' at one end $(0$ $\mathrm{mm})$ and 'very severe' pain at the other $(100 \mathrm{~mm})$. The patients were re-examined 30 minutes after receiving the first dose and then hourly for the first 8 hours of the study. At each assessment time, patients were asked to rate the severity of their pain and also to assess pain relief, again using a similar visual analogue scale, marked 'no relief' at 
one end $(0 \mathrm{~mm})$ and 'complete relief' at the other end $(100 \mathrm{~mm})$. Subsequently, they were evaluated at the end of each treatment day, when pain severity and pain relief were evaluated using the same visual analogue scale evaluation. At the end of each study day and at the end of the study, both patients and investigators provided an overall evaluation of the efficacy of treatment rating it as excellent, very good, good, fair or poor. Pain at the injection site was also evaluated each day, 8 and 24 hours after administering the first injection on that day, and measured according to the following scale: no pain, mild pain, moderate pain or severe pain. Adverse events were reported spontaneously by the patient at each monitoring time or recorded by the investigator, using indirect questioning.

Scores for analogue pain intensity difference (APID) were calculated as the difference between the initial pain intensity and the subsequent half-hour or hourly value. The sum of analogue pain intensity differences, calculated as the area under the APID by time curve (SAPID), and the maximum APID during the 8-hour period, were calculated for each patient, as was the area under the analogue pain relief score by time curve (TOTAPAR).

\section{Statistical analysis}

A descriptive statistical analysis was performed for each variable and both treatment groups were analyzed to confirm their comparability at the commencement of the study. Student's and Mann Whitney's U tests were used for the quantitative variables, and the Pearson's $\chi^{2}$-test was used for qualitative variables.

Within-group efficacy was analyzed using non-parametric tests for paired data; these analyses were performed to study the changes in clinical signs, over time, within each treatment group. The main part of the statistical analysis focused on evaluating differences in efficacy and tolerance between treatment groups, using the MannWhitney test for quantitative variables and contingency tables $\left(\chi^{2}\right.$-test with Yates' correction when necessary) for qualitative variables. Results were considered statistically significant for $\mathrm{p}<0.05$.

\section{RESULTS}

A total of 60 patients was enrolled of whom 30 received ketorolac and 30 received buprenorphine. There were 2 protocol violators, 1 in each treatment group, who took medication which was not allowed. The remaining 58 patients were included in the analyses. The two groups of patients were comparable in terms of age, sex, weight and severity of pain before the study commenced (Table I).

During the first 6 hours after the initial dose of study drug, statistically significant differences favouring buprenorphine were found for SAPID at 3 hours $(p=0.0440)$, SAPID at 6 hours $(\mathrm{p}=0.0300)$, TOTAPAR at 3 hours $(\mathrm{p}=0.0259)$ and TOTAPAR at 6 hours ( $\mathrm{p}=0.0134)$, (Table II). However, 'time to first positive APID' and 'time to peak APID' were not statistically different between the groups, indicating a similar time to onset of action. Similarly, there was not a significant difference between the groups with respect to peak APID, indicating a comparable reduction in pain scores (Table III). 
The daily evaluation of pain severity at the end of Days 1, 2 and 3 showed no statistically significant differences between the two treatments, nor were there significant differences in pain relief at the end of Days 1 or 3 , although pain relief at the end of Day 2 was significantly greater in the buprenorphine group.

The study medication was given on an 'as needed' basis and a comparison was made between the number of doses administered in each treatment group. The average number of doses on the first day was 2.88 for ketorolac and 2.74 for buprenorphine; on the second day, the number was 2.62 for ketorolac and 2.21 for buprenorphine, and on the third day, 0.69 for ketorolac and 0.95 for buprenorphine. These were not statistically significantly different on any of the study days.

According to the investigator's and patient's daily overall assessment of efficacy, no statistically significant differences were observed between the treatment groups. Similarly, the final global assessment of efficacy, by both investigator and patient, revealed no significant differences between the treatments.

The differences in the number of patients completing the study in each treatment group were not statistically significant $(\mathrm{p}=0.7590)$; however, there was a considerable difference in the number of withdrawals due to absence of pain (20 in the ketorolac group and 10 in the buprenorphine group) (Table IV). There was also a statistically significant difference in the number of patients withdrawing due to adverse events; only $1(3.4 \%)$ of 29 patients treated with ketorolac and 11 (37.9\%) of 29 patients treated with buprenorphine were withdrawn from the study due to adverse events $(\mathrm{p}<0.001)$.

Similarly, the total number of patients reporting adverse events was considerably less in the ketorolac group (Table V). A total of 7 ketorolac patients reported adverse events, 1 of whom complained of moderate malaise and discontinued the treatment. Of the remaining 6 patients, their complaints were mostly mild, and consisted of nausea (3 patients), drowsiness ( 1 patient), headache (1 patient), and gastro-intestinal pain (1 patient).

In the buprenorphine group, 21 patients reported adverse events, 11 of whom discontinued the treatment. The adverse reactions amongst the patients who withdrew were nervous system complaints, somnolence, dizziness, drowsiness, confusion, nausea and vomiting. Some patients experienced more than 1 event. The pattern of adverse events reported by patients who continued in the study was similar to the above, but less severe.

\section{DISCUSSION}

The immediate post-operative period is characterized by the highest levels of pain experienced by surgical patients. It is during this time that a potent, fast acting intramuscular analgesic is needed. The choice of an analgesic drug is always balanced by the risk/benefit ratio. The physician has to choose an efficacious drug with the best adverse effects profile. The use of a narcotic in this situation is highly effective but a drawback to its use is the high incidence of side-effects and its potential for abuse. ${ }^{8-10}$ 
In this study, $30 \mathrm{mg}$ ketorolac up to 4-times a day as needed, was compared to $0.3 \mathrm{mg}$ buprenorphine up to 4-times a day, in order to assess comparative efficacy and tolerance. The results of this study indicate that ketorolac is an appropriate choice for the treatment of moderate to very severe pain in the early post-operative period and that it compares favourably with buprenorphine in efficacy, and was better tolerated.

An important issue in the evaluation of an analgesic agent indicated for post-operative pain is the speed with which its analgesic effect is manifested. Rapid onset of action has traditionally been considered an important attribute of the narcotic analgesics such as buprenorphine. Analysis of the onset of analgesic activity in this study revealed that this feature is virtually identical for ketorolac (31.2 minutes) and buprenorphine (30 minutes). Although in the first 8-hour period buprenorphine resulted in a significant lower pain intensity and higher pain relief, scores at the end of each study day showed no statistically significant differences between the two treatments, except with respect to pain relief which was better in the buprenorphine group at the end of Day 2. Of more importance to the clinical situation than the actual pain scores at a particular time is the overall view of the treatment, which in this study was assessed at the end of each day and at the end of the study. There were no differences between the treatments regarding the patients' and the investigator's opinion.

With respect to the tolerability, the complaints were mainly related to the nervous system and the digestive system. There were marked differences between the treatments. In the ketorolac group, $24 \%$ of patients reported adverse events and for buprenorphine-treated patients, $72.4 \%$ reported adverse events. There were also fewer withdrawals due to adverse events (3\% with ketorolac and $38 \%$ with buprenorphine).

Overall, the results of this study show that $30 \mathrm{mg}$ intramuscular ketorolac up to 4-times a day as needed is efficacious in the treatment of moderate to severe post-orthopaedic surgery pain. In this setting, ketorolac compares favourably with $0.3 \mathrm{mg}$ buprenorphine up to 4-times a day as needed, both in analgesic potency and in rapidity of onset, and is associated with a statistically significantly better tolerability profile $(\mathrm{p}<0.01)$.

\section{ACKNOWLEDGEMENTS}

We gratefully acknowledge the contribution of Jordi Sarroca, M.D., and Cristina Suñer, Ph.D., who performed the statistical analysis, and Mrs. Silvia Ferré for her secretarial support throughout this research project.

\section{REFERENCES}

1. Conrad, K. A., Fagan, T. C., Mackie, M. J., and Mayshar, P. V., (1988). Effects of ketorolac tromethamine on hemostasis in volunteers. Clin. Pharmacol. Ther, 43, 542-546.

2. Estenne, B., Julien, M., Charleux, H., Arsac, M., Arvis, G., and Loygue, J., (1988). Comparison of ketorolac, pentazocine and placebo in treating postoperative pain. Curr Ther. Res., 43, 1173-1183. 
3. Guzmán, A., Yuste, F., Toscano, R. A., Young, J. M., Van Horn, A. R., and Muchowski, J. M., (1986). Absolute configuration of (-)-5-benzoyl-1,2-dihydro$3 \mathrm{H}-$ pyrrolo $(1,2-\mathrm{a})$ pyrrole-l-carboxylic acid, the active enantiomer of ketorolac. J. Med. Chem., 29, 589-591.

4. Montoya-Iraheta, C., Garg, D. C., Jallad, N. S., Morszczak, E. S., Yee, J. P., Renneke, G. A., and Weidler, D. J., (1986). Pharmacokinetics of single dose oral and intramuscular ketorolac tromethamine in elderly vs young healthy subjects (Abstract). J. Clin. Pharmacol., 26, 545.

5. Mroszczak, E. J., Lee, F. W., Combs, D., Sarnquist, F. H., Huang, B. L., Wu, A. T., Tokes, L. G., Maddox, M. L. and Cho, D. K., (1987). Ketorolac tromethamine absorption, distribution, metabolism, excretion, and pharmacokinetics in animals and humans. Drug Metab. Dispos., 15, 618-626.

6. Mroszczak, E. J., Ling, T., Yee, J., Massey, I., Phil, D., and Sevelius, H., (1985). Ketorolac tromethamine absorption and pharmacokinetics in humans (Abstract). Clin. Pharmacol. Ther, 37, 215.

7. Rooks, W. H., Maloney, P. J., Shott, L. D., Schuler, M. E., Sevelius, H., Strosberg, A. M., Tanenbaum, L., Tomolonis, A. J., Wallach, M. B., Waterbury, D., and Yee, J. P., (1985). The analgesic and anti-inflammatory profile of ketorolac and its tromethamine salt. Drugs Exp. Clin. Res., 11, 479-492.

8. Vangen, O., Doessland, S., and Lindbaek, E., (1988). Comparative study of ketorolac and paracetamol/codeine in alleviating pain following gynaecological surgery. J. Int. Med. Res., 16, 443-451.

9. Yee, J. P., Bradley, R., Stanski, D., and Cherry, C., (1986). A comparison of analgesic efficacy of intramuscular ketorolac tromethamine and meperidine in postoperative pain. Clin. Pharmacol. Ther., 39, 237.

10. Yee, J. P., Koshiver, J. E., Allbon, C., and Brown, C. R., (1986). Comparison of intramuscular ketorolac tromethamine and morphine sulfate for analgesia of pain after major surgery. Pharmacother, 6, 253-261. 
Table 1. Details of the patients studied: number of patients and mean $( \pm$ S.D. $)$ values

\begin{tabular}{|l|c|c|}
\hline Patients & Ketorolac & Buprenorphine \\
\hline No. studied & 29 & 29 \\
\hline Sex: Male & 12 & 17 \\
\hline Female & 17 & 12 \\
\hline Age (years) & $47.17 \pm 16.99$ & $41.34 \pm 14.57$ \\
\hline Weight $(\mathrm{kg})$ & $64.69 \pm 8.99$ & $70.10 \pm 11.87$ \\
\hline Height $(\mathrm{cm})$ & $162.52 \pm 9.12$ & $167.48 \pm 8.49$ \\
\hline Anaesthesia: & & \\
\hline General & 26 & 6 \\
\hline Other & 3 & $74.0 \pm 16.5$ \\
\hline Baseline pain intensity $(\mathrm{mm})$ & $69.7 \pm 16.9$ & 23 \\
\hline
\end{tabular}

\begin{tabular}{|l|c|c|c|}
\hline \multicolumn{5}{|c|}{ Table 2. Assessments of treatment efficacy during the first 6 hours: mean values } \\
\hline Assessment & Ketorolac $(\mathbf{n}=\mathbf{2 9})$ & Buprenorphine $(\mathbf{n}=\mathbf{2 9})$ & P value \\
\hline SAPID & & & \\
\hline After 3 hours & 149.6 & 176.1 & 0.0440 \\
\hline After 6 hours & 314.1 & 372.9 & 0.0300 \\
\hline TOTAPAR & & & \\
\hline After 3 hours & 234.8 & 249.5 & 0.0259 \\
\hline After 6 hours & 492.4 & 526.0 & 0.0134 \\
\hline
\end{tabular}

Table 3. Assessment of peak analogue pain intensity difference (APID): mean values

\begin{tabular}{|l|c|c|c|}
\hline Assessment & Ketorolac $(\mathbf{n = 2 9 )}$ & Buprenorphine $(\mathbf{n}=29)$ & P value \\
\hline $\begin{array}{l}\text { Time to first positive } \\
\text { APID (hours) }\end{array}$ & 0.52 & 0.50 & 0.3173 \\
\hline $\begin{array}{l}\text { Time to peak APID } \\
\text { (hours) }\end{array}$ & 2.40 & 2.16 & 0.1550 \\
\hline Peak APID (mm) & 60.4 & 67.8 & 0.1456 \\
\hline
\end{tabular}


Table 4. Reasons for patients withdrawing from the study: number of patients

\begin{tabular}{|l|c|c|}
\hline Reason & Ketorolac $(\mathbf{n = 2 9 )}$ & Buprenorphine $(\mathbf{n}=\mathbf{2 9})$ \\
\hline No further pain & 20 & 10 \\
\hline Adverse events & $1 *$ & 11 \\
\hline Lack of efficacy & 1 & \\
\hline Patient request & 1 & \\
\hline$* \mathrm{p}<0.001$, difference between groups \\
\hline
\end{tabular}

Table 5. Summary of adverse events reported: number of patients

\begin{tabular}{|c|c|c|}
\hline Adverse events & Ketorolac $(\mathbf{n = 2 9 )}$ & Buprenorphine $(\mathbf{n = 2 9})$ \\
\hline No. patients reporting & 7 & 21 \\
\hline No. patients reporting: & 22 & 8 \\
\hline No events & 7 & 10 \\
\hline 1 event & & 3 \\
\hline 2 events & & 37 \\
\hline 3 events & 7 & 11 \\
\hline Total no. events reported & 1 & 8 \\
\hline $\begin{array}{l}\text { No. patients discontinuing } \\
\text { because of adverse events }\end{array}$ & & \\
\hline
\end{tabular}

